\title{
Luis Álvarez FaLcón (Ed.) \\ LA SOMBRA DE LO INVISIBLE. \\ MerleaU-Ponty 1961-2011 (Siete lecciones) \\ MADRID, EUTELEQUIA, 2011, 347 PP.
}

por Emilio Ginés Morales Cañabate

Nos encontramos ante un libro que desentraña las sombras que surgen en nuestro entorno visible. En efecto, lo que percibimos es el mundo desplegado a nuestro alrededor extendiéndose todo él y enseñoreando su potencia para ser captado con claridad; pero algo nos dice que esta no es toda la verdad. Podemos decir que el objetivo fundamental de este libro es aportar claridad a uno de los puntos más impactantes y, a la vez, más ambiguos del filósofo existencialista, pues su finalidad no es otra que "iluminar la invisibilidad que todo lo visible deja traslucir". El valor del libro que comentamos reside en que sus artículos enfocan el problema inacabado de la aparición del sentir invisible que hay en toda percepción, la cual, como decía Maurice Merleau-Ponty, abarca tanto el derecho como el revés del cuerpo empujando una dimensión hacia la otra.

Este vínculo no pudo ser convenientemente desentrañado debido a la muerte prematura de MerleauPonty; por ello, los profesores que imparten estas siete lecciones, apoyándose en su profundo conocimiento de este filósofo francés, nos ayudan con sus enseñanzas a desentrañar estas sombras en su movimiento indefinido. Esta dinámica que sentimos en nuestro interior se encuentra plagada de movimientos sinuosos que se religan para hacerse luz y claridad, en un paisaje cuya 
geografía se entreteje de carnalidad. La actividad de la carne posee una actividad que, dicho merleaupontianamente, "segrega tanto desde dentro como desde fuera", dejando en su estela dinámica la sensación de que hay algo que todavía está por inaugurarse.

Así pues, la metodología general en la que se moverán los autores consiste en partir de una fenomenología de la génesis (61), en donde la materialidad se percibe no como una extensión pasiva a todo estímulo, sino como preñada de una intencionalidad latente e inacabada que está todavía por significarse. De tal manera será así que la conformación eidética del mundo pierde su esencia de "estructura de identidad" para convertirse en "estructura de orientación" (63).

Este cambio de paradigma frente a la tradición de una conciencia absoluta y pura pone a la idea y a la conciencia en tela de juicio, pues toda síntesis pasiva en realidad se encuentra preñada de actividad. Lo que tradicionalmente se ha denominado esencia y existencia, no es ya vista como una "promoción luminosa del ser a la conciencia" (ib.) ya que la esencia permanece en nuestra memoria corporal formando complejos sensibles y preobjetivos que nutren continuamente nuestra mirada sobre el mundo. La verdadera conciencia pasará de ser ese ente puro que la tradición del pensamiento había construido a convertirse en movimiento espontáneo, propio de la contingencia inacabada que tiene lugar ante todo acontecer mundano.

1. La primera lección de esta obra que reseñamos, "MerleauPonty desde el materialismo fenomenológico", está firmada por Ricardo Sánchez de Urbina. Comienza con lo expuesto en la introducción acerca de esa conciencia interior defendida por la tradición y a la que Merleau-Ponty combatió durante toda su vida. Tan encerrada se encontraba esta conciencia en el interior que, más que formar parte de nosotros, nos manipulaba, ya que con su contenido perfectamente visible y objetivo nos incitaba a constituir como inamovibles una gran cantidad de datos y hechos en nuestro pensamiento, los cuales fijan el dinamismo propio de la percepción de los fenómenos en conceptos, palabras o figuras geométricas perfectamente pre-visibles. Yo no soy el espectador puro que, por el acto de la ideación, va a llegar a ser; yo soy un campo de experiencias, donde se dibujan solamente la familia de las 
cosas materiales así como también de otras familias (147). Por lo tanto, para el autor, como para MerleauPonty, hay un cruce entre el cuerpo y el mundo donde más que encontrarnos con conceptos puros nos hallamos ante pliegues de nuestra carne en donde se guardan tanto las cosas visibles como aquellas que se esconden detrás de ellas. En efecto, la pasividad del concepto y la actividad del cuerpo con que percibimos el mundo en continua manifestación naciente no deja de ampliar su horizonte; por lo tanto, hay una zona del fenómeno que oteamos y que ingenuamente creemos acotada con lo que vemos, y sin embargo una $y$ otra vez descubrimos que hay en ella una actividad invisible, movimiento que engendra diferencia respecto a lo ya establecido.

2. La segunda lección, "Phantasia y experiencia estética. Los límites de la vida subjetiva", tiene como autor a Luis Álvarez Falcón. En esta lección, retoma el testigo de esta diferencia continua que nos ofrecen los sentidos y que es siempre naciente, la cual aflora cada vez que el sujeto tiende hacia el mundo. A partir del punto cero, que es nuestro propio cuerpo carnal, se producen grados de libertad que se manifies- tan en una no-coincidencia entre lo que percibimos como acabado y lo que todavía es posibilidad. El arte carnal serpentea en estos territorios indefinidos que se encuentran emparentados con la ensoñación a la que nos lleva lo irreflejo. MerleauPonty nos confirma sin duda el punto de vista del autor de esta lección en aquel momento de su obra en que nos religa la experiencia humana a la variedad interminable que todo análisis psíquico conlleva, el cual pretende ante todo -como decía el propio Merleau-Ponty"transformar las potencias de muerte en productividad poética".

3. En la tercera lección, "La sombra de la pasividad. Cuando la conciencia duerme", de Ma del Carmen López Sáenz, nos adentramos en el terreno de lo onírico que para nosotros es hermano de la poesía como metáfora y como totalidad. La ensoñación es propia de un tipo de conciencia singular que se deja traspasar por la irreflexión, pero que, de la misma forma que se fundamenta en ella, también es a partir de ésta que nos aporta un sentido de situación frente al mundo. Como nos dice la autora de forma clarificadora, "la conciencia perceptiva descansa en la onírica" (144). En 
todo sueño, donde el cuerpo está aparentemente en situación pasiva, hay en realidad una multitud de sinestesias y de movimientos expresivos que agitan la relación profunda del individuo con su mundo interior, en el que se encuentran también implicadas sus experiencias vividas en el mundo externo. En realidad, en el momento del sueño es donde mejor se refleja para Merleau-Ponty que interior $y$ exterior no son dimensiones separadas sino que una y otra se alimentan mutuamente en un mismo sujeto, en el que conviven de forma promiscua el ser y el mundo (173). Esta connivencia nos cubre de tal manera que precisamos, para salir del sueño que nos embarga, un despertar paulatino que nos sirva de interludio a las lecciones que forman la segunda parte de este libro.

4. La cuarta lección, "MerleauPonty y el hecho artístico", inicia esta segunda parte del libro, y tiene como autora a Maryvonne Saison. En efecto, despertar puede ser visto como co-nacer con el mundo, ya que cada vez que abrimos los ojos después del sueño diario damos existencia a una relación que prosigue al contemplar la obra de la creación ante nuestros ojos y, por lo tanto, al continuar su percepción cotidiana, como el artista ante un lienzo, lanzados a "co-nocer" nuevos caminos, es decir, a dar extensión a lo que ya sabíamos prolongándolo con aportaciones innovadoras. Hay algo y se trata solamente de saber si es verdaderamente este espacio, este tiempo, este movimiento, este mundo que creemos ver y sentir. Lo que Merleau-Ponty nos propone es dar un giro radical hacia nuestra experiencia y no quedarnos embebidos en la contemplación de la pureza de lo ya formado que ha perdido su expresividad, sino debilitarnos hasta reencontrarnos con un algo cuya esencia no es inmutabilidad o solidez, sino -al decir de él- "variación total". Lo que el artista pone en juego cada vez que intenta plasmar su ser en un lienzo o en un escenario no es la parte más sólida de sí mismo, sino su ser más débil que renovado se continúa en su producción. Del mismo modo, el ser humano que comienza el día emerge de la promiscuidad de la noche en la que todo él se encontraba, para diferenciarse como yo que da sentido a toda experiencia. En definitiva, hombres y mujeres somos artistas y creadores de nuestra propia vida. 
5. La quinta lección, "El weberianismo de Merleau-Ponty", está desarrollada por Josep Maria Bech. Se nos habla en ella de que las manifestaciones tanto socio-históricas como culturales son inapresables conceptualmente. Si quisiéramos pensarlas como inamovibles negaríamos nuestras percepciones, dado que cuando teorizamos acerca de ellas, tal y como pensaba el sociólogo alemán Weber, olvidamos que ellas cambian con nosotros, y que no se puede reducir su dinamismo ni a través de conceptos ni de "tipos ideales". La actividad corporal de cada hombre es donadora de sentido; pero no unívoco, sino abierto a diferentes grados de asociaciones y combinaciones posibles. Weber, según señala Bech, es consciente de que la construcción social nada tiene que ver en las afecciones con que vivimos; de hecho estamos sometidos a una doble naturaleza, obligados como estamos de hecho a la comunidad social a la vez que al cuerpo. Interpreta el proceso histórico de la racionalización en Occidente como una distancia creciente entre, por un lado, los seres humanos concretos $y$, por otro, sus afectos y la satisfacción más o menos inmediata de sus necesidades (216). Por lo tanto, podemos resaltar que una cosa son los procesos de racionalización, las construcciones teóricas, con las que queremos dar un sentido axiológico a la realidad, y otra cosa es el trasfondo salvaje que hay bajo estas estructuras racionales. Lo que existe es un tejido de relaciones comunitarias que dan lugar a una "no coincidencia" flagrante entre la construcción pensada de la realidad y ese entramado invisible que no deja de expandirse y ganar espacio, dilatándose en el horizonte. Frente a lo evidente que son los núcleos históricos que describimos para fundamentar con la razón el porqué y el para qué de la construcción social, se encuentra lo no tan evidente. Tal y como nos dice el filosofo existencialista, "la verdadera historia vive totalmente a costa nuestra" (221). Es decir, es la acción del ser humano $-y$, por lo tanto, el propio ser humano- lo que cambia la cultura en donde se desenvuelve y en esta actividad se da siempre una "deformación coherente" de lo que ya está dado, modulándose continuamente la realidad socio-cultural que no deja de innovarse. En la realidad, la cultura es, por lo tanto, una "secreción" (224) de toda esta actividad que el ser humano establece con el mundo. El historiador, recogiendo todo este 
acontecer, lo interpreta y forma una estructura con pretensiones cientificistas que pretenden objetivar la sociedad, la cultura o la historia. Esta exigencia esencialista será criticada vivamente por MerleauPonty, ya que es siempre la experiencia la que ha de sustentar la esencial. Nos encontramos, para el autor de este artículo, fuera de la "ideología de la trasparencia" (231), puesto que ninguno de los factores que conforman lo social puede revelarse de forma tan trasparente que nos muestre una relación causal directa en donde no intervengan las creencias $y$, por lo tanto, las diferentes perspectivas que éstas nos ofrecen. Es en la ligazón salvaje que se forma entre todos los elementos del entramado social donde logramos entrever algo de su sentido, el cual se ofrece de una forma "parcial" (ib.). Pero el mismo pintor es un hombre que trabaja, que vuelve a encontrar todas las mañanas en la figura de las cosas la misma interrogación, la misma llamada a la que no ha dejado de responder. Para él, su obra no está nunca hecha, está siempre en curso, de manera que nadie puede prevalerse de ella contra el mundo. Un día, la vida se esquiva, el cuerpo se sustrae; otras veces, y más tristemente es la pre- gunta diseminada a través del espectáculo del mundo, la que cesa de pronunciarse. Bech insiste en una filosofía del arte que trasforme la cultura y la sociedad en acción creadora ya que ambas son dimensiones activas y vivientes en la medida que protegen nuestro modo de vida moviéndose a la par que toda experiencia humana (235). La realidad, como en los sueños, no coincide con lo que vemos de forma extensa, la institucionalización no es sólida sino flexible ya que se construye en un horizonte que por su invisibilidad la vemos conformarse a medida que se desarrolla. Como nos sugiere el autor, podríamos decir que la profundidad del horizonte interior vive en la encrucijada con el horizonte exterior en el que vivimos (238). Como consecuencia hemos de decir que en todo "núcleo de sentido" surge un "núcleo de ausencia" (240). Y este pasaje es el que forma lo que denominamos trascendencia, es decir, lo posible que hay en toda génesis de sentido. Para Bech, desde nuestro punto de vista, el por-venir se mantiene a distancia de lo ya dado, situado en la sombra de la opacidad que todo interrogante conlleva. Por lo tanto, MerleauPonty abre en la filosofía un nuevo territorio, progresista sin duda, en el 
que inaugurar la verdad de la sociedad basándose en la "no-presencia" (245).

6. En la sexta lección, "Mundo perceptivo y mundo cultural. Merleau-Ponty y la filosofía de la cultura", de Mario Teodoro Ramírez' asistimos al desarrollo que este autor hace de este mundo lleno de posibilidades que se infiltran en todo lo que el hombre percibe. Esto es lo que significa la primacía de la percepción: no que todo se reduce a la percepción, sino que la percepción está en todo (255). La percepción no es solo un acto unilateral o solitario sino que surge dentro de un paisaje en el que toda relación que se da entre los cuerpos, hace posible el enriquecimiento y la apertura del horizonte dentro de este campo en el que nos movemos. ¿Qué significa entonces percepción? Como decíamos, no se trata ante todo de acto de conciencia, no es un hecho mental (lo que toda la tradición nos había empujado a suponer). El acontecimiento perceptual más bien lo podemos definir como una estructura de campo, donde respecto a un punto cero -el sujeto corporal y sensible- se articula un entorno de diversos elementos, configurados en ciertas líneas de fuerza [...] un esce- nario que se capta desde cierto punto de vista (257). Por esto el autor nos alienta a percibir en nuestra cultura, ese lado invisible que no está ya dado definitivamente sino que se abre a lo que somos capaces de hacer y de obrar, por lo tanto a nuestra actividad creativa en la que afirmamos antes que una tradición que heredamos y que nos define, una existencia que se abre a lo inesperado. El mundo antes que un lugar de cosas ya dadas, es sin embargo un escenario en el que nuestras acciones se encuentran implicadas con los otros, y en donde todas las relaciones corporales son posibles para articular con sus movimientos distintos sentidos, dentro de un campo de experiencia que recoge toda la variedad posible. El arte es la expresión por excelencia -prolongación y realización- del mundo de la percepción: del cuerpo viviente y del sintiente, de la carne del ser, de la materialidad fenoménica, del escenario y del paisaje del mundo percibido. Testigo y testimonio del primer contexto y la primigenia contextura de todo lo existente (257). Para nosotros es muy interesante, a partir de este análisis trasformador que hace el autor de este capítulo, pensar que la existencia misma no es un conjunto de re- 
gularidades ya pactadas, sino que se encuentra sujeta a innovaciones. Como afirma Merleau-Ponty, no están fuera de nosotros sino que nacen en nosotros del mismo modo que nosotros en ellas. Este sentido progresista y social, en cierto modo optimista, que inició Merleau-Ponty, nos abre el camino hacia el cambio continuo $\mathrm{y}$, por lo tanto, hacia la esperanza, ya que ella solo es posible si aquello que creamos puede transformarse. Trasformación es sumirse en la interrogación que toda actividad creadora plantea a lo ya instituido porque, como bien afirma el autor de esta lección, cultura no es solo saber sino ante todo percibir y sentir (259).

7. Todo esto nos lleva a la séptima y última lección, "Mundo perceptivo y mundo cultural", desarrollada por César Moreno Márquez, en la que nos habla del ser en su cualidad de frágil a la vez que de resistente. En su texto, el autor incide especialmente en un aspecto que Merleau-Ponty convirtió en el eje trasversal de su filosofía, esto es, en la importancia del primum vivere frente al cogitare. César Moreno incide en el hecho cotidiano de existir y en la vida diaria como primordial, incluso como más primor- dial que el pensar. Merleau-Ponty [...] enfatizaba la lucidez de una autoconciencia obligada a enfrentarse con numerosas oscuridades y todo ese fluir de vida que nos aparta de la autoconciencia y la reflexión, como queriendo demostrarnos que esa autoconciencia y reflexión pueden ser importantes para el filosofo, pero que a veces son secundarias en el ejercicio espontáneo, incluso salvaje, diario, del vivir (286). Por lo tanto, el ser para Merleau-Ponty, como nos dice César Moreno, no es el corte que se produce entre acción y pensamiento, entre cuerpo y espíritu; el ser es más bien la imposibilidad de que exista la coincidencia entre ambos, como si debieran cortejarse indefinidamente el uno al otro, esperando hacer surgir del torbellino de lo visible algún territorio común entre ambos. Esta nueva territorialidad que de cuando en cuando sale de lo invisible para darse a la luz, nos afirma que existe algo que puede sostener el dialogo existencial entre la acción corporal y la propia del pensamiento, pues, al fin, ambos son movimientos entrelazados el uno al otro. En la realidad puede darse cierta armonía que es sin duda fugaz, como la sensación que tiene el pintor de haber captado algo que al plasmarlo en su obra se 
torna huidizo. Lo que amaba Merleau-Ponty en Cezanne debía ser, ante todo, ese estar allí disfrutando de la armonía de lo sensible entre-lovisible-y-lo-invisible. Ese algo ciertamente nos sigue como una sombra mientras vivimos, en la naturaleza, en la creación propia del arte, en los sueños, en la cultura y en la sociedad en la que nos movemos. Esta quelque chose no es sino nuestro propio gesto que se refleja en el del otro haciendo surgir entre ambos núcleos de ser en los que aprendemos a conocernos como individuos que existimos en convivencia con otros.

De estas sombras invisibles que, sin embargo, vemos tan tangiblemente nos habla este libro tan singular al que hemos tratado de acercarnos aquí. 